\title{
The Gene Encoding Peripheral Myelin Protein Zero Is Located on Mouse Chromosome 1
}

\author{
Rainer Kuhn, ${ }^{1}$ Dimitrina Pravtcheva, ${ }^{2}$ Frank Ruddle, ${ }^{2}$ and Greg Lemke ${ }^{1}$ \\ 'Molecular Neurobiology Laboratory, The Salk Institute, San Diego, California 92138, and 'Department of Biology, Yale \\ University, New Haven, Connecticut 06511
}

\begin{abstract}
We have used somatic cell hybrids to map the gene encoding protein zero $\left(\mathbf{P}_{0}\right)$, the major structural protein of peripheral myelin. Analysis of Southern blots of DNA obtained from these hybrids allows us to unambiguously assign the $P_{0}$ gene to mouse chromosome 1 . This observation indicates that mutations in the $P_{0}$ gene do not account for Trembler, a chromosome 11 mutation that specifically affects myelination in the peripheral nervous system.
\end{abstract}

The elaboration of myelin, the electrical insulation that surrounds all rapidly conducting axons in vertebrates, involves the induction of a number of glial-specific genes (Lemke, 1988). In the PNS, the most prominent of these induced genes encodes the major structural protein of peripheral myelin, protein zero $\left(\mathrm{P}_{0}\right) . \mathrm{P}_{0}$ is a $30-\mathrm{kDa}$ integral membrane glycoprotein that accounts for over $50 \%$ of PNS myelin protein (Greenfield et al., 1973; Ishaque et al., 1980). It is restricted in its expression to myelin-forming Schwann cells, the principal glial cells of the PNS: it is not expressed by either CNS glia or by the large number of nonmyelinating Schwann cells that populate many peripheral nerves (Brockes et al., 1980; Lemke, 1988). $\mathrm{P}_{0}$ exhibits structural similarity to immunoglobulins and immunoglobulin-related cell adhesion proteins (Lai et al., 1987; Lemke et al., 1988) and has been hypothesized to function as a membrane adhesion molecule and to thereby promote and maintain the very tight compaction of apposed membrane surfaces characteristic of myelin (Kirschner and Ganser, 1980; Lemke and Axel, 1985; Lemke et al., 1988).

I.ike $\mathbf{P}_{0}$, the mouse mutation Trembler is restricted in its expression to the PNS and, most strikingly, to myelin-forming Schwann cells (Falconer, 1951; Henry et al., 1983; Hogan and Greenfield, 1984). Mice carrying this mutation exhibit generalized tremors as a result of hypomyelination of peripheral nerves that, in the wild type, are heavily myelinated (e.g., the sciatic nerve). Although the trembling phenotype is evident in heterozygotes, the mutation is semidominant, in that there are clear gene dosage effects with respect to the extent of hypomyelination

\footnotetext{
Received May 19, 1989; accepted June 21, 1989.

We thank Dr. Keith Fournier for providing the $F(11) \mathrm{J}$ and $\mathrm{FB}(11) \mathrm{J}$ cell lines Drs. Catherine Thompson and Ron Evans for the c-erbA probe, Drs. David McElligot and Glen Evans for the IL-3 probe, and Dr. Klaus Nave for instruction in the preparation of mouse genomic DNA. This work was supported by grants from the NIH (G.L. and F.R.) and the National Multiple Sclerosis Society (to G.L.). G.L. is the recipient of a Pew Scholars Award from the Pew Memorial Trusts, and of a Basil O'Connor Starter Scholar Award from the March of Dimes.

Correspondence should be addressed to Greg Lemke, Molecular Neurobiology Lab-South, The Salk Institute for Biological Studies, P.O. Box 85800, San Diego, CA 92138.

Copyright (C) 1990 Society for Neuroscience $0270-6474 / 90 / 010205-05 \$ 02.00 / 0$
}

and the steady-state levels of major myelin proteins (Fryxell, 1983). Two alleles of Trembler, $T r$ and $T r^{j}$, have been described. $\operatorname{Tr} / \operatorname{Tr}$ homozygotes exhibit a nearly complete lack of peripheral myelin, but are viable under laboratory conditions. $T^{i} / T r$ homozygotes also exhibit severe hypomyelination, but die 2-3 weeks after birth (Henry and Sidman, 1988). The Trembler gene has been genetically mapped to mouse chromosome 11 (Davisson and Roderick, 1978), and expression of this gene has been unambiguously demonstrated to be Schwann cell autonomous (Bray et al., 1981). Thus, wild-type Schwann cells myelinate the axons of Trembler neurons, but Trembler Schwann cells are incapable of myelinating wild-type axons (Aguayo et al., 1977; Bunge et al., 1980). In addition to a hypomyelinating phenotype, Trembler Schwann cells exhibit an inability to withdraw from the proliferative state that normally precedes differentiation (Low, 1976; Perkins et al., 1981). This extended proliferation, which often results in the formation of "onion bulb" tumors, is also restricted to myelinating cells: Trembler nerves that are largely unmyelinated (e.g., the sympathetic trunk) are populated by a normal number of Schwann cells whose appearance is indistinguishable from wild type (Perkins et al., 1981).

The parallel expression of $\mathrm{P}_{0}$ and the Trembler gene product has led to the suggestion that they are identical. We have tested this hypothesis directly. We have used a cloned rat $\mathrm{P}_{0}$ cDNA, together with a set of DNAs prepared from mouse-hamster and mouse-rat somatic cell hybrids, to map the $P_{0}$ gene to mouse chromosome 1 and to exclude the possibility of a second $P_{0}$ gene located on mouse chromosome 11. This finding demonstrates that the PNS-specific Trembler mutation does not involve any direct alteration in the structure of the major PNSspecific myelin gene, but must instead result from the alteration of an as-yet-unidentified gene uniquely expressed by myelinating Schwann cells.

\section{Materials and Methods}

Probes. Southern blots of genomic DNA from mouse-hamster and mouserat hybrid lines were probed with the $1.85-\mathrm{kb}$ EcoRI insert of a nearly full-length clone of the rat $P_{0}$ cDNA (pSN63) (Lemke and Axel, 1985). This DNA was labeled to high specific activity by nick translation or random hexamer priming using $\alpha^{32} \mathrm{P}$-deoxynucleotides, and hybridized at high stringency to Southern blots according to standard procedures (Maniatis et al., 1982).

Cell lines and DNAs. Fifteen different hybrid cell lines, prepared by fusion of the E36 Chinese hamster cell line with the CMS4TG and MethA mouse sarcoma cell lines, were used, together with 1 line prepared from microcell fusions of C57BL/6J mouse embryo fibroblasts with rat FTO-2B hepatoma cells. The preparation and karyotyping of these lines have been described previously (Pravtcheva et al., 1983; Killary and Fournier, 1984). The chromosome composition of the mouse- 


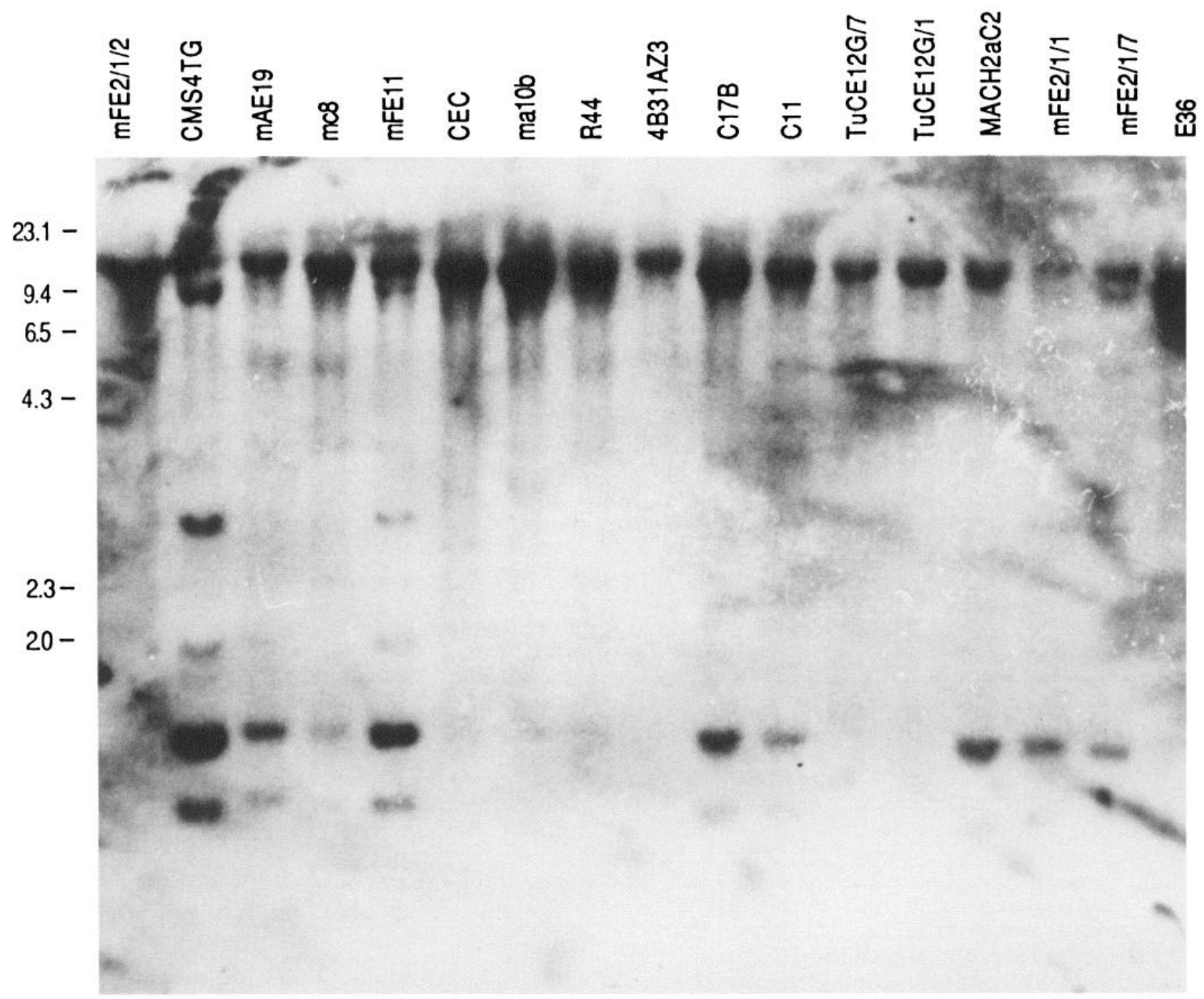

Figure 1. $\mathrm{P}_{0}$ gene is located on mouse chromosome 1. Southern blot hybridization of the rat $\mathrm{P}_{0}$ cDNA to genomic DNA isolated from mousehamster hybrid cell lines. Genomic DNA (20 $\mathrm{g}$ each lane) was isolated from the indicated mouse-hamster hybrid cell lines, digested with BamHI, resolved on an agarose gel, Southern-blotted, and probed with a full-length, nick-translated rat $\mathrm{P}_{0} \mathrm{cDNA}$ probe. Size markers are in kilobases and mark the migration of $\lambda$ HindIII standards.

hamster cell lines used in this study is summarized in Table 1 . The mouse-rat line used- $\mathrm{F}(11) \mathrm{J}-$ contains only mouse chromosome 11 on a complete background of rat chromosomes (Killary and Fournier, 1984). Genomic DNA $(20 \mu \mathrm{g})$ from each mouse-hamster line was digested with BamHI, resolved on agarose gels, and blotted onto nylon (Hybond) membranes for Southern analysis. Restriction digests using BamHI, EcoRI, HindIII, PstI, and XbaI (10 $\mu \mathrm{g}$ each digest) were similarly analyzed for the $F(11) \mathrm{J}$ rat-mouse hybrid line.

\section{Results and Discussion}

We analyzed BamHI restriction digests of genomic DNA prepared from the 15 mouse-hamster hybrid cell lines described in Table 1, together with DNA from the CMS4TG parental mouse and E36 parental Chinese hamster lines. BamHI was chosen for these digests since it generates a number of distinctive

Figure 2. $\mathrm{P}_{0}$ gene is not located on mouse chromosome 11. A, Southern blot hybridization of a rat $\mathrm{P}_{0}$ cDNA to genomic DNA isolated from either C57BL/6J mouse liver $(M), \mathrm{F}(11) \mathrm{J}$ rat-mouse hybrid cells $(R / M)$, or back-selected $\mathrm{FB}(11) \mathrm{J}$ cells $(R)$. $\mathrm{F}(11) \mathrm{J}$ cells contain mouse chromosome 11 on a complete rat background, while $\mathrm{FB}(11) \mathrm{J}$ cells carry only rat chromosomes. DNAs were cut with the indicated restriction enzymes and probed as described for Figure 1. Note that for each enzyme $R / M$ and $R$ lanes exhibit identical hybridization patterns, which are clearly distinguished from the patterns present in $M$ lanes. Size markers are in kilobases and mark the position of $\lambda$ HindIII standards. $B$, Secondary control Southern hybridization of a rat c-erbA cDNA to the HindIII, PstI, and XbaI digests from the blot in $A$. The c-erbA gene has previously been shown to reside on mouse chromosome 11. Arrowheads indicate restriction fragments shared between $M$ and $R / M$ lanes, but not present in $R$ lanes. The large ( $\sim 20$ kb) molecular weight fragment present in the $M$ lanes and absent from the $R / M$ lanes in the HindIII and PstI digests results from partial digestion of the C57BL/6J mouse genomic DNA. $C$, Secondary control Southern hybridization of a rat IL-3 cDNA probe to the same panel of digests displayed in $B$. Arrowheads indicate restriction fragments shared between $M$ and $R / M$ lanes, but not present in $R$ lanes. 
A

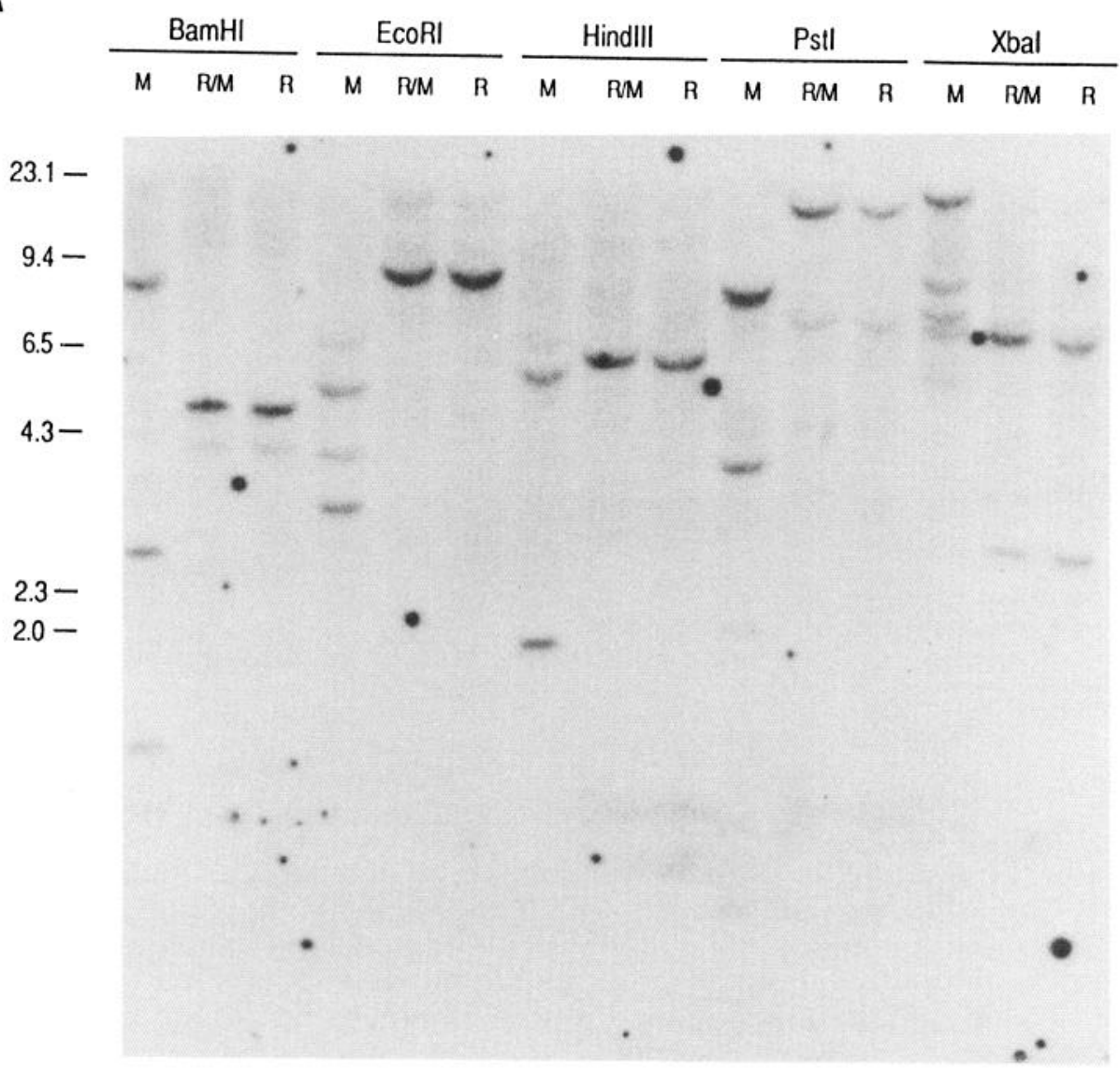

B

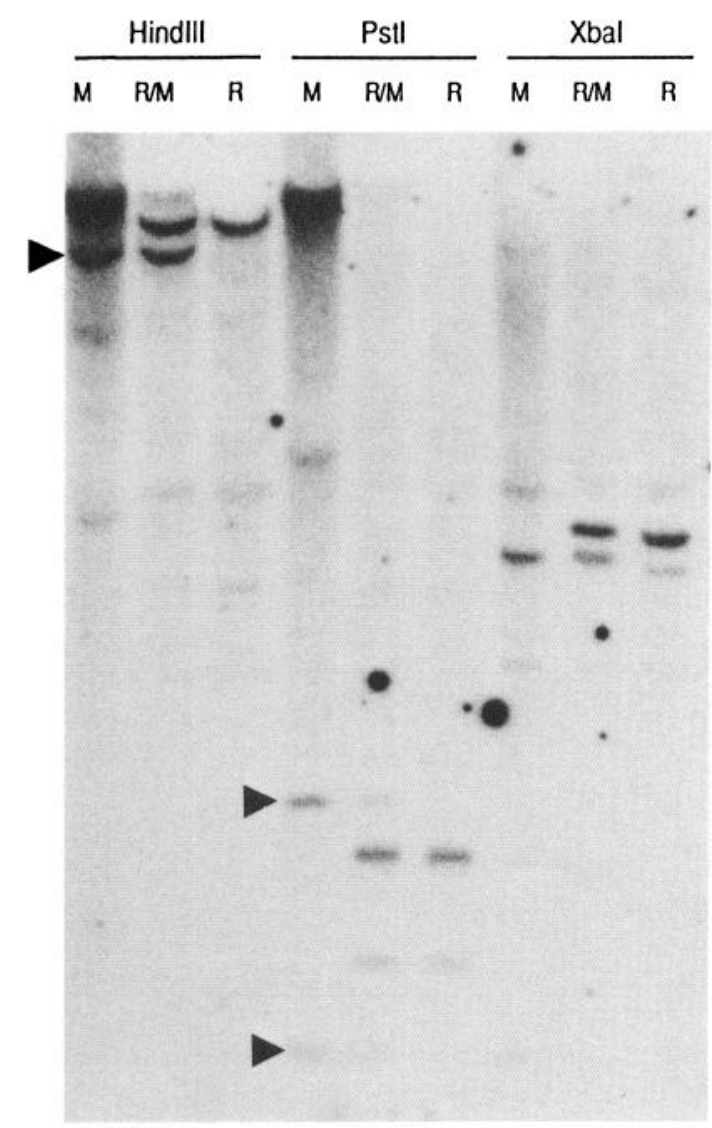

C
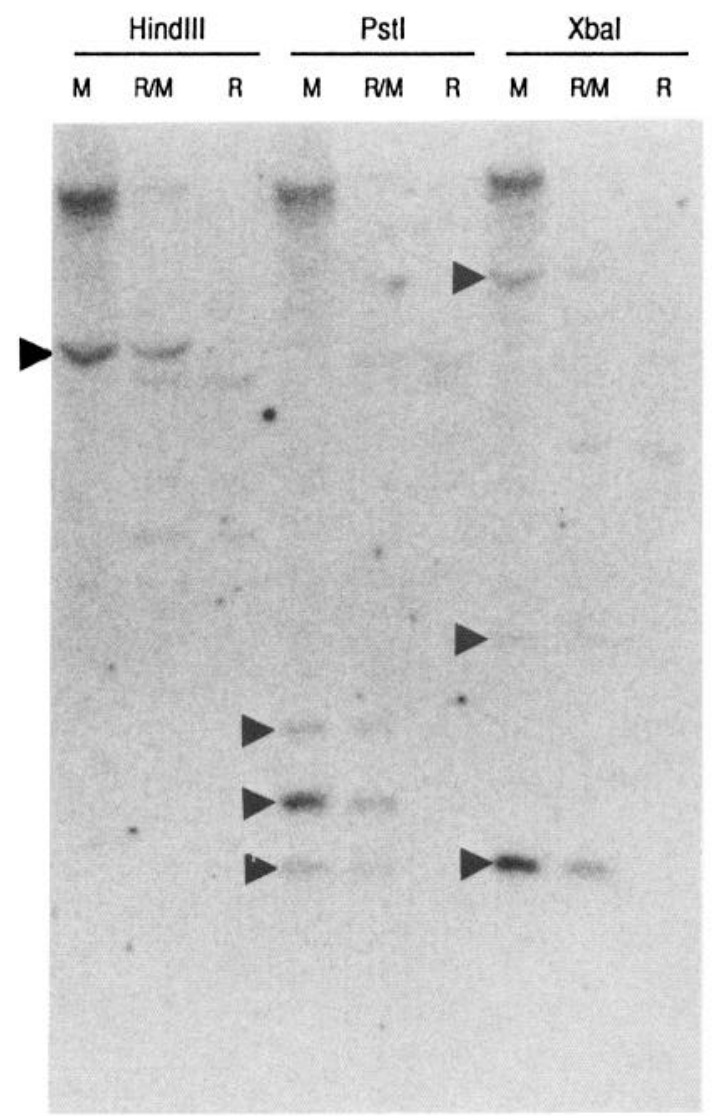


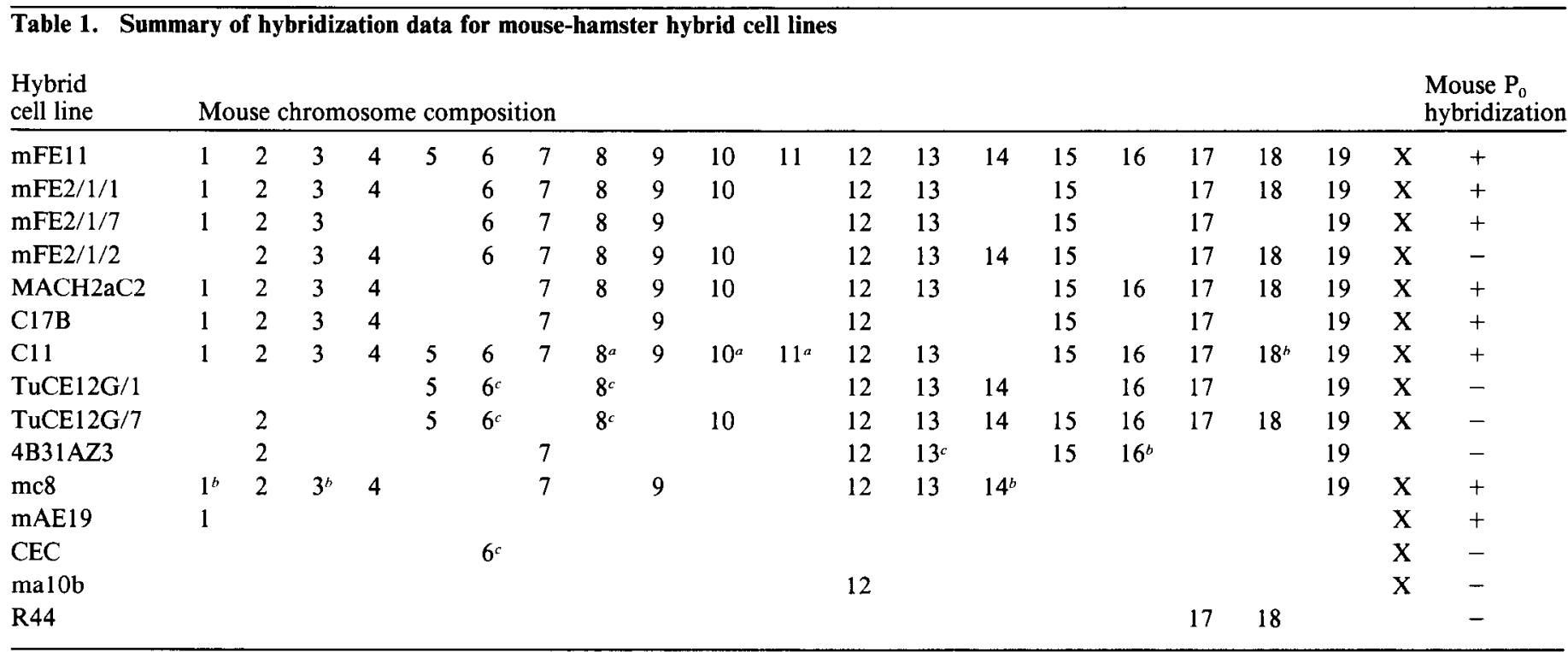

${ }^{a}$ Present in $10-15 \%$ of hybrid cells.

${ }^{\circ}$ Present in $<10 \%$ of hybrid cells.

c Rearranged chromosome.

lower-molecular-weight restriction fragments for the mouse $P_{0}$ gene (Lemke et al., 1988), but only a single very-high-molecularweight fragment for the hamster gene.

The segregation of mouse $P_{0}$ hybridization with mouse chromosome composition is indicated in Table 1 , and a typical Southern blot from which these data were derived is illustrated in Figure 1. The segregation pattern indicated in Table 1 unequivocally maps the $P_{0}$ gene to mouse chromosome 1 . For example, DNA from the mAE19 hybrid line, which contains only mouse chromosomes 1 and $X$, yields a mouse $P_{0}$ hybridization signal. In contrast, DNA from the ma10b hybrid line, which contains just mouse chromosomes $\mathrm{X}$ and 12, yields only the background hamster $\mathrm{P}_{0}$ hybridization signal. There is no discordance in the data presented in Table 1: the only lines that yield a mouse $P_{0}$ hybridization signal are those that contain mouse chromosome 1 .

As noted above and illustrated in Figure 1, hybridization to the mouse $P_{0}$ gene is easily distinguished from hybridization to the hamster gene. Given the exon-intron configuration of the cloned mouse gene (Lemke et al., 1988), BamHI bands of approximately 1.3 and $1.0 \mathrm{~kb}$ are predicted to yield the strongest hybridization signal when BamHI digests of mouse genomic DNA are analyzed with a full-length, nick-translated $P_{0} c D N A$ probe. (These bands contain the longest stretches of exon DNA colinear with the cDNA.) As illustrated in Figure 1, this is the result we obtained. The position of additional higher-molecularweight bands in some of the digests (e.g., CMS4TG) is, based on the BamHI restriction map of the cloned mouse $P_{0}$ gene (Lemke et al., 1988), consistent with partial fragmentation generated by incomplete digestion. In all of the BamHI digests performed, the background hamster gene is present as a large band of approximately $15 \mathrm{~kb}$. In general, the intensity of hybridization to the mouse $P_{0}$ gene is well correlated with the relative level at which mouse chromosome 1 is represented in a given hybrid population. Thus the mc8 line, in which mouse chromosome 1 is represented in less than $10 \%$ of the cells, yields a hybridization signal significantly lower than that for the
$\mathrm{MACH} 2 \mathrm{aC} 2$ line, in which this chromosome is present in approximately $70 \%$ of the cells.

These data unambiguously identify chromosome 1 as the carrier of the mouse $P_{0}$ gene. However, they do not exclude the formal possibility that an additional, identically configured $P_{0}$ gene is also present on mouse chromosome 11 . Since this chromosome is among the first to be lost in mouse-hamster hybrids, lines containing mouse chromosome 11 , but not mouse chromosome 1 , cannot be readily generated. In order to exclude the formal possibility of a second $\mathrm{P}_{0}$ gene on mouse chromosome 11 , we analyzed the segregation of mouse $P_{0}$ hybridization in a mouse-rat hybrid cell line containing only mouse chromosome 11 on a fixed, complete rat background (Killary and Fournier, 1984). The results of this analysis are shown in Figure 2. The hybridization pattern observed with restriction digests of DNA prepared from the $F(11) \mathrm{J}$ rat-mouse hybrid line, which contains mouse chromosome 11 , is identical to that of DNA prepared from a second line, $F B(11) J$. This line, a derivative of $F(11) \mathrm{J}$ in which loss of mouse chromosome 11 has been achieved through back-selection with bromodeoxyuridine, contains only rat chromosomes. The $\mathrm{F}(11) \mathrm{J} / \mathrm{FB}(11) \mathrm{J}$ pattern is easily distinguished from the $\mathrm{P}_{0}$ profile observed with digests of genomic DNA prepared from C57BL/6J mice (Fig. $2 A$ ), clearly indicating that mouse $P_{0}$ sequences are not present in the $F(11) J$ DNA.

The presence of mouse chromosome 11 in the $F(11) \mathrm{J}$ line was verified in 2 ways. First, the $\mathrm{F}(11) \mathrm{J}$ cells used to isolate the DNA analyzed in Figure 2 were grown in HAT medium to select for the presence of the thymidine kinase (TK) gene. This gene is located on mouse chromosome 11 and is uniquely provided by this chromosome in the $\mathrm{F}(11) \mathrm{J}$ mouse-rat hybrid, since the parental rat line used to generate the hybrid is TK- (Killary and Fournier, 1984). (TK- cells are killed in HAT medium.) Second, the blot shown in Figure $2 A$ was stripped and secondarily hybridized with cDNA probes for the c-erbA and interleukin-3 genes, which have been mapped to distal and proximal regions of mouse chromosome 11 , respectively, and which flank the Trembler locus (Zabel et al., 1984; Barlow et al., 1987; Thomp- 
son et al., 1987). These secondary hybridizations also indicated that mouse chromosome 11 DNA was in fact present in the F(11)J DNA analyzed. Figure 2, $B$ and $C$, illustrates the hybridization patterns observed for c-erbA and IL-3, respectively.

These results demonstrate that the $P_{0}$ gene resides on mouse chromosome 1 , and that $P_{0}$ sequences are absent from mouse chromosome 11. This finding in turn indicates that the PNSspecific Trembler mutation does not result from an alteration in the structure of the $P_{0}$ gene, which encodes the major PNSspecific myelin protein. Trembler should therefore be distinguished from myelination mutations such as jimpy and shiverer, which result from alterations in the structure of the genes encoding the major myelin proteins proteolipid protein and myelin basic protein, respectively (Roach et al., 1985; Nave et al., 1987). Indeed, the multifaceted phenotype exhibited by Trembler mice is more consistent with mutation of a regulatory, as opposed to structural, gene. An example of this sort of mutation is provided by sevenless (Banerjee et al., 1987), a mutation in Drosophila. In flies, the differentiation of 1 set of developing photoreceptor cells is controlled by their interaction with a second set of developing cells in a manner similar to that seen for the axonal control of Schwann cell differentiation and myelination. Sevenless pcrturbs this interaction much as Trembler perturbs the interaction of axons and Schwann cells. Given that Trembler has been precisely mapped and has been shown to be expressed in a Schwann cell-autonomous fashion, we hope to characterize the molecular basis of this important mutation by identifying novel Schwann cell-specific mRNAs transcribed from genes located on mouse chromosome 11.

\section{References}

Aguayo, A. J., M. Attiwell, J. Trecarten, S. Perkins, and G. M. Bray (1977) Abnormal myelination in transplanted trembler mouse Schwann cells. Nature 265: 73-75.

Banerjee, U., P. J. Renfranz, J. A. Pollack, and S. Benzer (1987) Molecular characterization and expression of sevenless, a gene involved in neuronal pattern formation in the Drosophila eye. Cell 49: 281291.

Barlow, D. P., M. Bucan, H. Lehrach, B. L. M. Hogan, and N. M. Gough (1987) Close genetic and physical linkage between the murine haematopoietic growth factor genes GM-CSF and multi-CSF (IL-3). EMBO J. 6: 617-623.

Bray, G. M., M. Rasminsky, and A. J. Aguayo (1981) Interactions between axons and their sheath cells. Annu. Rev. Neurosci. 4: 127162.

Brockes, J. P., M. C. Raff, D. J. Nishiguchi, and J. Winter (1980) Studies on cultured rat Schwann cells. III. Assays for peripheral myelin proteins. J. Neurocytol. 9:67-77.

Bunge, R. P., M. B. Bunge, E. Okada, and C. Cornbrooks (1980) Abnormalities expressed in cultures prepared from peripheral nerve tissues of trembler and dystrophic mice. In Neurological Mutations Affecting Myelination, N. Baumann, ed., INSERM Symposium No. 14, pp. 433-446, Elsevier/North Holland, Amsterdam.

Davisson, M. T., and T. H. Roderick (1978) Status of the linkage map of the mouse. Cytogenet. Cell Genet. 22: 552-564.

Falconer, D. S. (1951) Two new mutants, "trembler" and "reeler," with neurological actions in the house mouse (Mus musculus). J. Genet. 50: 192-201.

Fryxell, K. F. (1983) Biochemical and Genetic Studies of Peripheral Myelination in Normal Development and in the Mouse Mutant Trembler. Ph.D. Dissertation, California Institute of Technology, Pasadena.

Greenfield, S., S. Brostoff, E. H. Eylar, and P. Morell (1973) Protein composition of myelin of the peripheral nervous system. J. Neurochem. 20: 1207-1216.

Henry, E. W., and R. L. Sidman (1988) Long lives for homozygous Trembler mutant mice despite virtual absence of peripheral nerve myelin. Science 241: 344-346.

Henry, E. W., J. S. Cowen, and R. L. Sidman (1983) J. Neuropathol. Exp. Neurol. 42: 688-699.

Hogan, E. L., and S. Greenfield (1984) Animal models of genetic disorders of myelin. In Myelin, 2nd ed., P. Morell, ed., pp. 489-534, Plenum, New York/London.

Ishaque, A., M. W. Roomi, I. Szymanska, S. Kowalski, and E. H. Eylar (1980) $\mathrm{P}_{0}$ glycoprotein of peripheral nerve myelin. Can. J. Biochem. 58: 913-921.

Killary, A. M., and R. E. K. Fournier (1984) A genetic analysis of extinction: Trans-dominant loci regulate expression of liver-specific traits in hepatoma hybrid cells. Cell 38: 523-534.

Kirschner, D. A., and A. L. Ganser (1980) Compact myelin exists in the absence of basic protein in the shiverer mutant mouse. Nature 283: 207-210.

Lai, C., M. A. Brow, K.-A. Nave, A. B. Noronha, R. H. Quarles, F. E. Bloom, R. J. Milner, and J. G. Sutcliffe (1987) Two forms of 1B236/ myelin-associated glycoprotein, a cell adhesion molecule for postnatal neural development, are produced by alternative splicing. Proc. Natl. Acad. Sci. USA 84: 4227-4341.

Lemke, G. (1988) Unwrapping the genes of myelin. Neuron 1: 535543.

Lemke, G., and R. Axel (1985) Isolation and sequence of a cDNA encoding the major structural protein of peripheral myelin. Cell 40 : 501-508.

Lemke, G., E. Lamar, and J. Patterson (1988) Isolation and analysis of the gene encoding peripheral myelin protein zero. Neuron 1: 7383.

Low, P. A. (1976) Hereditary hypertrophic neuropathy in the Trembler mouse. J. Neurol. Sci. 30: 327-342.

Maniatis, T., E. F. Fritsch, and J. Sambrook (1982) Molecular Cloning pp. 387-389, Cold Spring Harbor Press, Cold Spring Harbor, NY.

Nave, K.-A., F. E. Bloom, and R. J. Milner (1987) A single nucleotide difference in the gene for myelin proteolipid protein defines the jimpy mutation in the mouse. J. Neurochem. 49: 1873-1877.

Perkins, C. S., A. J. Aguayo, and G. M. Bray (1981) Schwann cell multiplication in Trembler mice. Neuropathol. Appl. Neurobiol. 7: 115-122.

Pravtcheva, D. D., F. H. Ruddle, R. W. Ellis, and E. M. Scolnick (1983) Assignment of murine cellular Harvey ras gene to chromosome 7 . Somatic Cell Genet. 9: 681-686.

Roach, A., N. Takahashi, D. Pravtcheva, F. Ruddle, and L. Hood (1985) Chromosomal mapping of mouse myelin basic protein gene and structure and transcription of the partially deleted gene in shiverer mutant mice. Cell 42: 149-155.

Thompson, C. C., C. Weinberger, R. Lebo, and R. M. Evans (1987) Identification of a novel thyroid hormone receptor expressed in the mammalian central nervous system. Science 237: 1610-1614.

Zabel, B. U., R. E. K. Fournier, P. A. Lalley, S. C. Naylor, and A. Y. Sakaguchi (1984) Cellular homologs of the avian erythroblastosis virus erbA and erbB genes are syntenic in mouse but asyntenic in man. Proc. Natl. Acad. Sci. USA 81: 4874-4878. 